\title{
Influence of neoadjuvant treatment of rectal carcinoma on operability and incidence of distant metastases
}

\author{
Prausova $\mathrm{J}^{1}$, Kubackova $\mathrm{K}^{1}$, Dusek L ${ }^{2}$, Vinakurau $\mathrm{S}^{1}$, Pikus $\mathrm{T}^{1}$, Malinova $\mathrm{B}^{1}$, Hoch $\mathrm{J}^{3}$, \\ Kodet $\mathrm{R}^{4}$, Linke $\mathrm{Z}^{1}$
}

Department of Radiotherapy and Oncology, University Hospital Motol, V Uvalu 84, 15008 Prague, Czech Republic. katerina.kubackova@fnmotol.cz

\begin{abstract}
In the Czech Republic, rectal carcinoma does not only represent a medical problem, but also a socioeconomic one. At our department, we treated totally 266 patients with rectal carcinoma in the years 1998 through 2006. Among our patients, neoadjuvant treatment led to a reduction in size of the tumour in $37.6 \%$, in $50.8 \%$ the size did not change. In T3 tumours, the reduction in size was observed in $36.7 \%$ of the patients and did not change in $56 \%$; in T4 tumours, the reduction in size was observed in $60 \%$ of the patients. In $88 \%$ of the patients who underwent the operation, no residual tumour was found, in $9 \%$ of patients, a residual tumour was detected. In $19 \%$ of the patients, a local recurrence of the tumour was detected. A statistically significant relationship was proved between the appearance of the metastatic disease and the presence of angioinvasion and the size of the primary tumour according to the Duke's classification (Tab. 1, Fig. 4, Ref. 20). Full Text in PDF www.elis.sk. Key words: rectal carcinoma, neoadjuvant treatment, chemo-radiotherapy before surgery, angioinvasion.
\end{abstract}

In the Czech Republic, the incidence rate of rectal carcinoma has recently reached 20.7 per 100000 population and mortality rate has reached 10.1 per 100000 population (data from the year 2007). The incidence increases steeply from 50 years of age. The Czech Republic is ranked among the countries with the highest incidence of this disease. According to the latest Czech population data from the year 2007, the proportions of the stages of rectal carcinoma is as follows: stage I. $22.9 \%$, stage II $20.4 \%$, stage III $24.1 \%$, stage IV $21.7 \%$ and $10.9 \%$ of newly diagnosed cases are unstaged mostly due to objective reasons, like a very advanced disease, early death, patient's refusal of anti-tumour therapy, generally poor health status of a patent, etc..

Surgical approach is the basis of therapy for the clinical stages II and III. In contrary to the early stage I, enough evidence from clinical studies has been collected over the last decade to support a treatment strategy combining chemotherapy and radiotherapy for the stages II and III. These studies were inspired by the frequent appearance of local relapses but also distant metastases in patients treated solely surgically. The results of these studies had clearly shown that a combined therapeutic approach leads to a significantly lower incidence of relapses $(1-4)$.

The goal of our retrospective analysis is to ascertain the effect of neoadjuvant treatment on the reduction of size of the primary

${ }^{1}$ Department of Radiotherapy and Oncology, University Hospital Motol, Prague, Czech Republic, ${ }^{2}$ Institute of Biostatistics and Analyses, Masaryk University, Brno, Czech Republic, ${ }^{3}$ Department of Surgery, University Hospital Motol, Prague, Czech Republic, and ${ }^{4}$ Department of Pathology and Molecular Medicine, University Hospital Motol, Prague, Czech Republic

Address for correspondence: K. Kubackova, Department of Radiotherapy and Oncology, University Hospital Motol, V Uvalu 84, CZ-150 06 Prague, Czech Republic. tumour, achieving operability and affecting the incidence of early generalization of the disease.

\section{Patients and methods}

In the period 1998-2006, we treated at our department totally 266 patients diagnosed with rectal carcinoma. 102 of the patients were females, with the median age of 64 years (ranging 29-89 years); 164 were males with the median age of 60 years (ranging 26-84 years) (Fig. 1). $6 \%$ of the tumours were of the stage T2, $82 \%$ stage $\mathrm{T} 3$ and $11 \%$ stage T 4 ; in $1 \%$ of the patients the tumour stage was undeterminable. The proportion of the clinical stages I, II, III, and IV were $5.6 \%, 72.2 \%, 14.7 \%$, and $2.3 \%$ respectively, in $5.3 \%$ of the patients, the clinical stage was undeterminable. $42 \%$ of the tumours were localized less than $5 \mathrm{~cm}$ from the anus. 244 patients (92\%) underwent a surgical procedure, of which $38 \%$ underwent neoadjuvant chemo-radiotherapy, $54 \%$ only radiotherapy. $52.8 \%$ of the patients in the age group younger than 50 years underwent a simultaneous neoadjuvant chemo-radiotherapy, as compared to merely $12.3 \%$ of the patients of 70 years or more. Concomitant chemo-radiotherapy was given to $41 \%$ of the patients with a T3 tumour and to $33 \%$ with a T4 tumour. $53 \%$ of patients with a T3 tumour and $37 \%$ of patients with a T4 tumour underwent radiotherapy without chemotherapy. The majority of the patients were treated with a concomitant regime with 5-fluorouracil (bolus or continual application) or capecitabin administered orally.

\section{Statistical analyses}

Standard rank summary statistics were used to describe the primary data, i.e. median, $\min / \max$ values and 5 th-95th percentile range. The non-parametric Mann-Whitney U test based on com- 
469-473

Sex

\section{$N=266$}

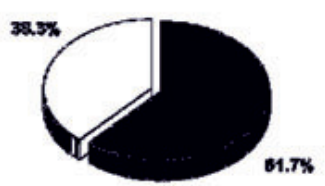

males ( $n=164)$ females $(n=102)$
Age at diagnosis

\begin{tabular}{lccc} 
& $\square$ Females & $\square$ Males & Total \\
\hline $\mathrm{N}$ & 102 & 164 & 266 \\
\hline Mean: & 63 years & 61 years & 62 years \\
Median: & 64 years & 60 years & 62 years \\
Range: & $29-89$ years & $26-84$ years & $26-89$ years \\
\hline
\end{tabular}

25

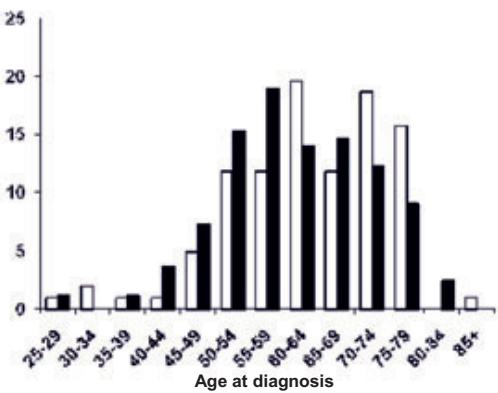

Fig. 1. Patient's sex and age.

parison of median values was applied to test differences between the compared variants in continuous variables. The maximum likelihood $\chi^{2}$ test was applied to test the differences between the variants in categorical variables. Correlation between parameters was tested using the Spearman's rank correlation coefficient. Survival outcomes were assessed using the standard Kaplan-Meier curves. The value $\mathrm{p}=0.05$ was taken as cut-off for a statistical significance in all applied tests.

\section{Results}

Of the patients who underwent neoadjuvant treatment, a total $37.6 \%$ had a reduction in size of the tumour, $50.8 \%$ had no change and only $2.6 \%$ had a progression of the primary tumour. Primary tumours of size T3 had a reduction in size in $36.7 \%$ and no change in size in $56 \%$, for T4 tumours it was $60 \%$ and $10 \%$ respectively; in the remaining $30 \%$ it was not possible to evaluate the change in size (Fig. 2). $8.3 \%$ of the patients were inoperable after the neoadjuvant treatment. There were $7.2 \%$ of inoperable patients following neoadjuvant radiotherapy, and $9.7 \%$ following the combined radio-chemotherapy. The median age of the inoperable patients was 65 years (ranging $47-82$ years). Inoperability rose with age, and the median age was 71 years among women and 64 years among men.

The most frequent type of surgical procedure was a resection of the rectum in $54.5 \%$ of the patients followed by an abdominoperineal resection in $37.7 \%$. Three patients underwent a protective colostomy, in 2 cases liver metastases were also resected during the operation, and in 1 patient a wedge resection of the urinary bladder was also performed. $69.3 \%$ of the operated patients were
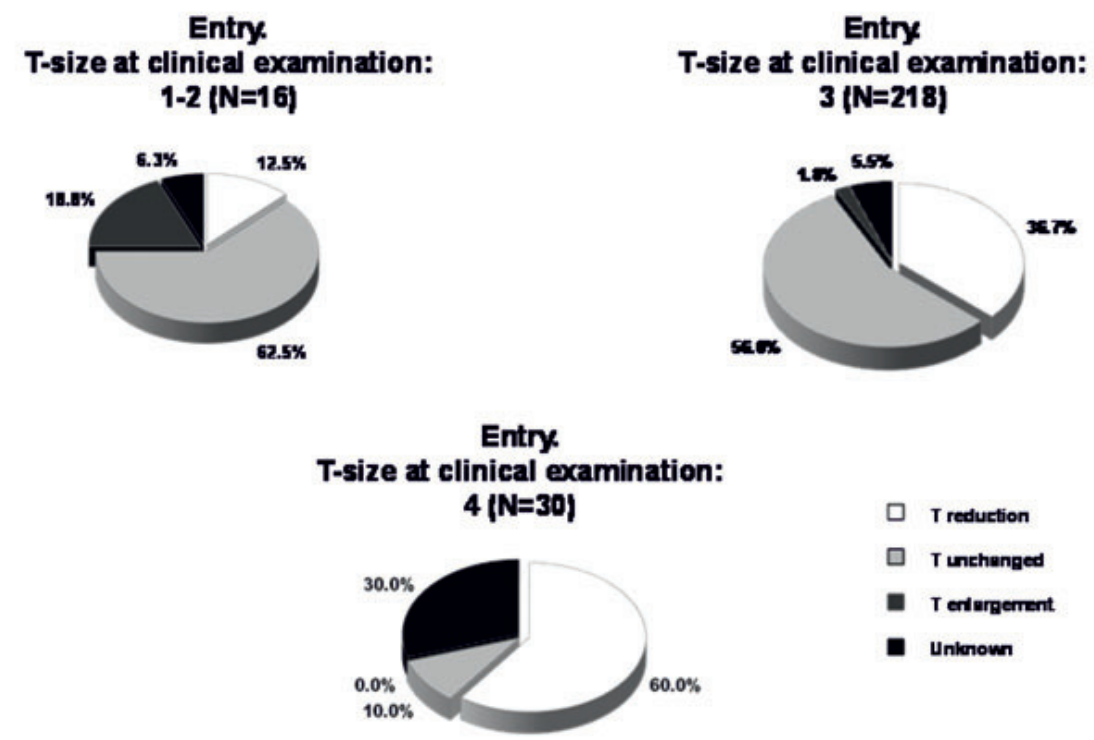

Fig. 2. Reduction of primary tumor our after neoadjuvant therapy. 

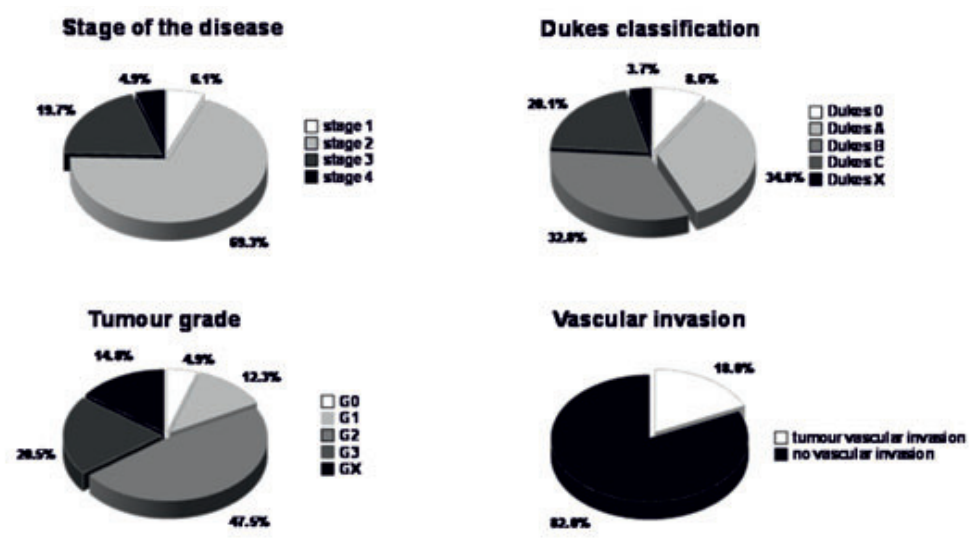

Fig. 3. Characteristics of patients undergoing surgery $(n=244)$.

\section{Relationship of number of examined and positive}

lymph nodes in patients undergoing surgery

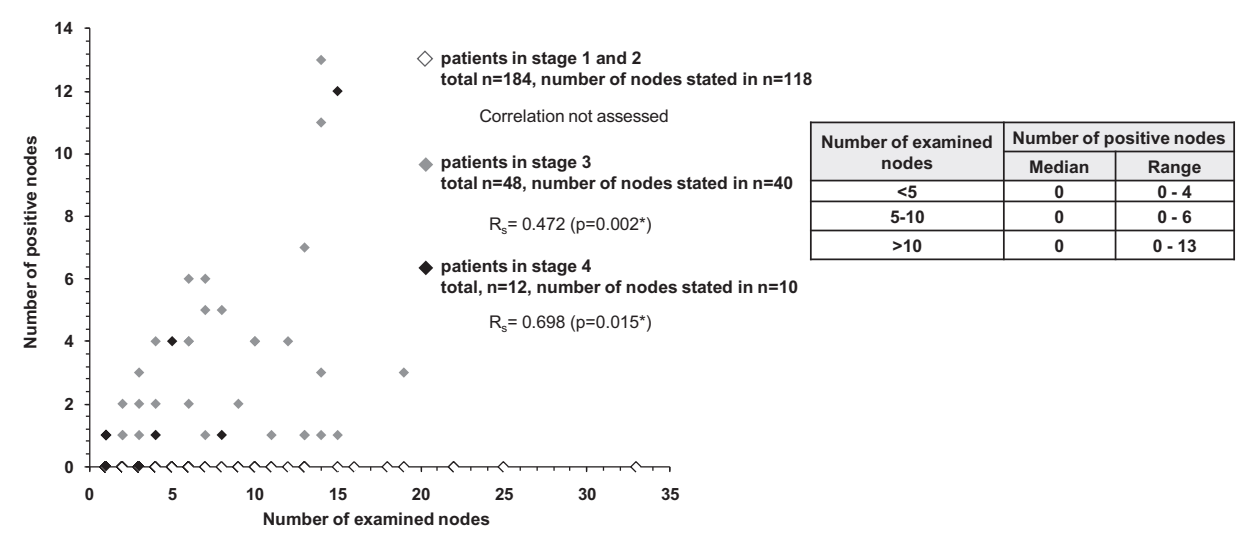

Fig. 4. Characteristics of patients undergoing surgery.

in the clinical stage II, $20 \%$ in the stage III and $5 \%$ in the stage IV. The histopathologic grading was determined as grade 1 in $12.3 \%$, grade 2 in $47.5 \%$, grade 3 in $20.5 \%$, and grade 4 in 14.8 $\%$. Angioinvasion was observed in $18 \%$ of the operated patients (Fig. 3). In a total of $88 \%$ of the operated patients, no residual tumour was found, as compared to merely $9 \%$ of patients where a residual tumor was still present. All 244 patients had their lymph nodes examined, but only in 168 cases we have the reports of the number of examined lymph nodes and positive lymph nodes. A statistically significant correlation between the number of examined lymph nodes and the number of lymph nodes containing a metastasis in the clinical stages III and IV was observed $(p<0.05)$ (Fig. 4). We detected a local recurrence of the tumour in $17.2 \%$ of the patients. The majority of cases of local recurrences were detected in patients in the clinical stage IV $-75 \%$ of the patients, followed by $19 \%$ in stage III and $13 \%$ in stages I and II together $(p<0.001)$. The appearance of distant metastases with a median time of 15 months since the end of treatment was noted in $19 \%$ of the patients. The metastases were detected predominantly in the patients who were inoperable $-27.3 \%$, of whom $15.7 \%$ underwent neoadjuvant chemo-radiotherapy and in $20.4 \%$ who underwent only neoadjuvant radiotherapy. A statistically significant relationship was determined between the appearance of metastatic disease and the presence of angioinvasion and the size of the tumour according to Duke's classification. The characteristics of patients with metastatic disease are summarized in the Table 1.

\section{Discussion}

In our retrospective analysis, we tried to evaluate the effects of neoadjuvant therapeutic approach in patients with rectal carcinoma who were treated at our department with standard treatment modalities and procedures.

A radical surgical operation with the resection of the primary tumour and a total mesorectal excision is the primary curative treatment modality for a locally advanced rectal carcinoma. The choice of solely surgical treatment leads to a $25-40 \%$ risk of developing a local recurrence $(5,6)$. Data from large randomized clinical studies have proven the benefits of preoperative treatment. Results of "The German Rectal Study Group" study have lead to the implementation of neoadjuvant chemo-radiotherapy of T3 and T4 tumours into the guidelines (3). This treatment modality has lead to the 
Tab. 1. Appearance of metastases after treatment.

\begin{tabular}{|c|c|c|c|c|}
\hline Factor & & $\mathrm{N}$ & $\begin{array}{c}\text { Metastases after } \\
\text { therapy }\end{array}$ & $\mathrm{p} 1$ \\
\hline \multirow[t]{2}{*}{$\overline{\operatorname{Sex}}$} & female & 102 & $19.6 \%$ & 0.887 \\
\hline & male & 164 & $18.9 \%$ & \\
\hline \multirow{4}{*}{$\begin{array}{l}\text { Age at } \\
\text { diagnosis }\end{array}$} & $<50$ years & 36 & $16.7 \%$ & 0.262 \\
\hline & 50-60 years & 86 & $15.1 \%$ & \\
\hline & $60-70$ years & 79 & $17.7 \%$ & \\
\hline & $>70$ years & 65 & $27.7 \%$ & \\
\hline \multirow[t]{3}{*}{ Stage } & stage $1+2$ & 196 & $16.3 \%$ & 0.158 \\
\hline & stage 3 & 52 & $26.9 \%$ & \\
\hline & stage 4 & 18 & $27.8 \%$ & \\
\hline \multirow[t]{3}{*}{$\mathrm{T}$} & $\mathrm{T} 1+2$ & 16 & $18.8 \%$ & 0.816 \\
\hline & Т 3 & 218 & $18.3 \%$ & \\
\hline & $\mathrm{T} 4$ & 30 & $23.3 \%$ & \\
\hline \multirow[t]{2}{*}{$\mathrm{N}$} & $\mathrm{N} 0+1$ & 210 & $17.6 \%$ & 0.359 \\
\hline & $\mathrm{N}>1$ & 42 & $23.8 \%$ & \\
\hline \multirow[t]{2}{*}{$\mathrm{M}$} & M 0 & 259 & $19.3 \%$ & 0.869 \\
\hline & M 1 & 6 & $16.7 \%$ & \\
\hline \multirow{3}{*}{$\begin{array}{l}\text { Tumour } \\
\text { location }\end{array}$} & $>5 \mathrm{~cm}$ from & 153 & $17.0 \%$ & 0.279 \\
\hline & anal orifice & & & \\
\hline & $\begin{array}{c}\text { up to } 5 \mathrm{~cm} \text { from } \\
\text { anal orifice }\end{array}$ & 112 & $22.3 \%$ & \\
\hline \multirow[t]{3}{*}{ Therapy } & $\begin{array}{c}\mathrm{RT}+\mathrm{CHT}+ \\
\text { surgery }\end{array}$ & 102 & $15.7 \%$ & 0.400 \\
\hline & RT + surgery & 142 & $20.4 \%$ & \\
\hline & inoperable & 22 & $27.3 \%$ & \\
\hline \multirow{4}{*}{$\begin{array}{l}\text { Duke } \\
\text { classification }\end{array}$} & Dukes 0 & 21 & $0.0 \%$ & $0.002 *$ \\
\hline & Dukes A & 85 & $14.1 \%$ & \\
\hline & Dukes B & 80 & $18.8 \%$ & \\
\hline & Dukes C & 50 & $32.0 \%$ & \\
\hline \multirow[t]{3}{*}{ Grade } & grade $0+1$ & 42 & $11.9 \%$ & 0.179 \\
\hline & grade 2 & 116 & $19.0 \%$ & \\
\hline & grade $3+4$ & 52 & $26.9 \%$ & \\
\hline \multirow{2}{*}{$\begin{array}{l}\text { Vascular } \\
\text { invasion }\end{array}$} & occured & 200 & $15.5 \%$ & $0.017^{*}$ \\
\hline & not occured & 44 & $31.8 \%$ & \\
\hline
\end{tabular}

shrinkage of the primary tumour and to the down-staging of the disease (7). On the other hand, there is no general consensus as to the treatment of T3 tumours without lymphadenopathy. It seems that in the case of patients undergoing a radical surgical procedure with clean edges and a sufficient number of lymph nodes examined (that is 12), the addition of radiotherapy into the combined neoadjuvant treatment is superfluous. This point of view is supported by the results of the German study with rectal carcinoma patients. In the group of patients pre-operatively diagnosed with a T3 tumour with negative lymph nodes, who underwent the operation without any neoadjuvant treatment were in fact in the stage pT1 to pT2. Some consider neoadjuvant treatment in this group of patients as superfluous. On the contrary, the Italian study of 42 patients who underwent neoadjuvant concomitant chemo-radiotherapy suggested that there was a possible benefit of this therapeutic approach in patients in the stage II (8). The most frequent stage in our group of 266 patients was T3 - $82 \%$, of whom $41 \%$ underwent neoadjuvant chemo-radiotherapy and merely $3.6 \%$ were found to be inoperable. In $36.7 \%$ of cases, we achieved down-staging of the tumour, in T4 tumours positive effects of neoadjuvant treatment were observed in $60 \%$ of the patients. Regression of the tumour following adjuvant chemotherapy was proven to be a significant prognostic marker (7). One of the aims of neoadjuvant treatment is the avoidance of having to perform an adbominoperitoneal resection and to lower the incidence of local recurrences. According to a recently published survey, the frequency of this operation currently ranges from $10 \%$ to $67 \%$ (9). In our group, a resection of the rectum prevailed in $54.5 \%$ and abdominoperitoneal resection with the necessity of permanent colectomy was performed in 37.7 $\%$ of the patients. The criteria of a radical resection were met in 88 $\%$ of the operations. As far as operability was concerned, similar effects were achieved for T3 and T4 tumours, irrespectively of whether simple radiotherapy or concomitant radio-chemotherapy was used. Even among the inoperable patients, the chosen neoadjuvant treatment did not differ. This group comprised primarily of older patients and female patients (the median age of women was 71 years, in men 64 years). We based the choice of the treatment modality predominantly on the performance status of the patient and his co-morbidities. The majority of our patients were treated with neoadjuvant chemotherapy consisting of 5-fluorouracil or capecitabine, only 5 of our patients with metastatic disease underwent concomitant chemotherapy with FOLFOX. The importance of adding oxaliplatin into the neoadjuvant treatment is supported by the study ACCORD 12/405, which compared concomitant chemo-radiotherapy comprising capecitabine against to the same treatment supplemented with oxaliplatin. The results did not prove any significant advantage of the combined chemotherapy and recommended capecitabine as "merits investigation" for T3 and T4 tumours (10). Attempts to increase the outcome of combined neoadjuvant chemo-radiotherapy have lead to numerous phase 2 studies with tumour targeted drugs. The results of the Italian study, which combined cetuximab and 5-fluorouracil with radiotherapy, have shown an acceptable toxicity, but surprisingly a low percentage of pathological responses (11). Two American studies had evaluated the effects of bevacizumab in combination with capecitabine or 5-fluorouracil. Both of these studies have proven the safety and tolerability of these combined neoadjuvant therapies and have recommended these combinations for further clinical studies with the emphasis on long term toxicity, finding biomarkers as predictors of response to treatment, post-operational course and the overall survival rate $(12,13)$.

Achieving a complete pathological remission seems to be a significant prognostic factor mainly in patients in clinical stage III and influences the choice of a further treatment modality (14). Currently, there is no general consensus concerning the necessity of adjuvant therapy after neoadjuvant treatment $(15,16)$; and this fact increases the importance of examining a sufficient number of lymph nodes as a part of the pathological staging. Lymph nodes were examined in the majority of our patients, but only in 168 cases we had exact numbers of examined and affected lymph nodes. We have proven a significant correlation between the number of examined lymph nodes and the number of lymph nodes containing metastases in the clinical stages III and IV among our patients. Affected lymph nodes were predominantly in the mesorectum, $5.7 \%$ in T1 tumours, $20 \%$ in T2 tumours, $65 \%$ in T3 tumours, and $78 \%$ in T4 tumours (17). The presence of lymph nodes containing metastases after the treatment with adjuvant radiotherapy is a significant negative prognostic factor. The persistence of metastases within the lymph nodes is 
connected with a higher cancer mortality rate and is a marker of a more aggressive tumour behavior with the need of further adjuvant systemic treatment (18). Among our patients, we have observed a relatively higher rate of local recurrences following neoadjuvant treatment, $19 \%$ in stage III and $13 \%$ in the stages I and II, which probably correlated with an insufficient number of examined lymph nodes and thus an inappropriate treatment regime. Local recurrences following neoadjuvant treatment in combination with modern surgical approaches including a total mesorectal excision had the rate of approximately $10 \%(19,20)$. The presence of angioinvasion, a negative prognostic factor, statistically significantly correlated with a more frequent rate of developing a metastatic disease. The systemic contribution of neoadjuvant chemo-radiotherapy probably lowered the incidence of distant metastases to the rate of $15.7 \%$ as compared to $20.4 \%$ of patients who merely underwent neoadjuvant radiotherapy without further adjuvant post-operative treatment.

Our treatment strategy of locally advanced rectal carcinoma was identical with the standards of other European centres specializing in the treatment of rectal carcinoma. Conditions in everyday setting with numerous co morbidities of the patients, their treatment preferences and often hardly accessible early staging examinations can significantly influence our decisions, but also the outcomes of the treatment as compared to clinical studies.

Despite the generally accepted standard treatment approach to pre-operative treatment of locally advanced rectal carcinoma, there are many unanswered questions. What is the optimal combination of cytostatic treatment and its combination with systemic targeted treatment? What is the optimal dose of radiotherapy and fractionation? There are controversies concerning chemo-radiotherapy in early T3 tumours with total mesorectal excision and genetic predictive and prognostic markers.

\section{References}

1. Kapiteijn E, Marijnen CA, Nagtegaal ID, Putter H, Steup WH, Wiggers T, Rutten HJ. Preoperative radiotherapy combined with total mesorectal excision for resectable rectal cancer. N Engl J Med 2001; 345 (9): 638-646.

2. Bosset JF, Collette L, Calais G, Mineur L, Maingon P et al. EORTC Radiotherapy Group Trial 22921. Chemotherapy with preoperative radiotherapy in rectal cancer. N Engl J Med 2006; 355 (11): 1114-1123.

3. Sauer R, Becker H, Hohenberger W, Rödel C, Wittekind et al. Preoperative versus postoperative chemoradiotherapy for rectal cancer. German Rectal Cancer Study Group. N Engl J Med 2004; 351 (17): 1731-1740.

4. Gérard JP, Conroy T, Bonnetain F, Bouché O, Chapet $O$, et al: Preoperative radiotherapy with or without concurrent fluorouracil and leucovorin in T3-4 rectal cancers: results of FFCD 9203. J Clin Oncol 2006; 24 (28): 4620-4625.

5. Havenga K, Enker WE, NorsteinJ, Moriya Y, Heald RJ et al. Improved survival and local control after total mesorectal excision or D3 lymphadenectomy in the treatment of primary rectal cancer:an international analysis of 1411 patinets. Eur J Surg Oncol 1999; 25: 368-374.

6. Nesbakken A, Nygaard K, Westerheim O, Mala T, Lunde OC. Local recurrence after mesorectal excision for rectal cancer. Eur J Surg Oncol 2002; 28 (2): 126-134.
7. Rödel C, Martus P, Papadoupolos T, Füzesi L, Klimpfinger M et al. Prognostic significance of tumor regression after preoperative chemoradiotherapy for rectal cancer. J Clin Oncol 2005; 23 (34): 8688-8696.

8. Pasetto LM, Friso ML, Pucciarelli S, Basso U, Rugge M et al. Role of neoadjuvant treatment in cT3N0M0 rectal cancer. Anticancer Res 2008; 28 (6B): 4129-4135.

9. Ota DM, Jacobs L, Kuvshinoff B. Rectal cancer: the sphincter-sparing approach. Surg Clin North Am 2002; 82 (5): 983-993.

10. Gérard JP, Azria D, Gourgou-Bourgade S, Martel-Laffay I et al. Comparison of Two Neoadjuvant Chemoradiotherapy Regimens for Locally Advanced Rectal Cancer: Results of the Phase III Trial ACCORD 12/0405-Prodige 2. J Clin Oncol 2010; 1638-1644.

11. Bertolini F, Chiara S, Bengala C, Antognoni P, Dealis C et al. Neoadjuvant treatment with single-agent cetuximab followed by 5-FU, cetuximab, and pelvic radiotherapy: a phase II study in locally advanced rectal cancer. Int J Radiat Oncol Biol Phys 2009; 73 (2): 466-472.

12. Crane CH, Eng C, Feig BW, Das P, Skibber JM et al. Phase II trial of neoadjuvant bevacizumab, capecitabine, and radiotherapy for locally advanced rectal cancer Int J Radiat Oncol Biol Phys 201; 76 (3): 824-830.

13. Willett CG, Duda DG, di Tomaso E, Boucher Y, Ancukiewicz M et al. Efficacy, safety, and biomarkers of neoadjuvant bevacizumab, radiation therapy, and fluorouracil in rectal cancer: a multidisciplinary phase II study. J Clin Oncol 2009; 27 (18): 3020-3026.

14. de Campos-Lobato LF, Stocchi L, da Luz Moreira A, Kalady MF, Geisler D et al. Downstaging without complete pathologic response after neoadjuvant treatment improves cancer outcomes for cIII but not cII rectal cancers. Ann Surg Oncol 201; 17 (7): 1758-1766.

15. Collette L, Bosset JF, den Dulk M, Nguyen F, Mineur L et al. European Organisation for Research and Treatment of Cancer Radiation Oncology Group. Patients with curative resection of cT3-4 rectal cancer after preoperative radiotherapy or radiochemotherapy: does anybody benefit from adjuvant fluorouracil-based chemotherapy? A trial of the European Organisation for Research and Treatment of Cancer Radiation Oncology Group. J Clin Oncol 2007; 25 (28): 4379-4386.

16. Quasar Collaborative G, Gray R, Barnwell J et al. Adjuvant chemotherapy versus observation in patients with colorectal cancer: a randomized study. Lancet 2007; 370: 2020-2029.

17. Sitzler PJ, Seow-Choen F, Ho YH, Leong AP. Lymph node involvement and tumor depth in rectal cancers: an analysis of 850 patients. Dis Colon Rectum 1997; 40 (12): 1472.

18. Chang GJ, Rodriguez-Bigas MA, Eng C, Skibber JM. Lymph node status after neoadjuvant radiotherapy for rectal cancer is a biologic predictor of outcome. Cancer 2009; 115 (23): 5432-5440.

19. Peeters KC, Marijnen CA, Nagtegaal ID, Kranenbarg EK, Putter $\mathbf{H}$ et al. The TME trial after a median follow-up of 6 years: increased local control but no survival benefit in irradiated patients with resectable rectal carcinoma. Ann Surg 2007; 246 (5): 693-701.

20. Visser O, Bakx R, Zoetmulder FA, Levering CC, Meijer S et al. The influence of total mesorectal excision on local recurrence and survival in rectal cancer patients: a population-based study in Greater Amsterdam 2007; 95 (6): 447-454.

Received May 2, 2011. Accepted January 12, 2013. 